\title{
The influence of working memory load on semantic priming
}

\section{Authors: Tom Heyman, Bram Van Rensbergen, Gert Storms, Keith A. Hutchinson, \& Simon De Deyne}

This is a postprint of an article that originally appeared in Journal of Experimental Psychology: Learning, Memory, and Cognition in May 2015.

Heyman, Tom, Bram Van Rensbergen, Gert Storms, Keith A. Hutchison, and Simon De Deyne. "The Influence of Working Memory Load on Semantic Priming." Journal of Experimental Psychology: Learning, Memory, and Cognition 41, no. 3 (May 2015): 911-920. DOI: https://dx.doi.org/10.1037/xlm0000050. 
The influence of working memory load on semantic priming

\author{
Tom Heyman $^{\mathrm{a}}$ \\ Bram Van Rensbergen ${ }^{\mathrm{a}}$ \\ Gert Storms ${ }^{\mathrm{a}}$ \\ Keith A. Hutchison ${ }^{\mathrm{b}}$ \\ Simon De Deyne ${ }^{\mathrm{a}}$ \\ ${ }^{a}$ University of Leuven, Tiensestraat 1023000 Leuven, Belgium \\ ${ }^{\mathrm{b}}$ Montana State University, P.O. Box 173440, Bozeman, MT 59717-3440 USA
}

Corresponding author:

Tom Heyman

Department of Psychology

University of Leuven

Tiensestraat 102

3000 Leuven, Belgium

E-mail: tom.heyman@ppw.kuleuven.be

Tel: +32473413888 


\begin{abstract}
The present research examines the nature of the different processes that have been proposed to underlie semantic priming. Specifically, it has been argued that priming arises as a result of automatic target activation and/or the use of strategies like prospective expectancy generation and retrospective semantic matching. This article investigates the extent that these processes rely on cognitive resources by experimentally manipulating working memory load. To disentangle prospective and retrospective processes, prime-target pairs were selected such that they were symmetrically associated (e.g., answer-question; SYM) or asymmetrically associated in either the forward direction (e.g., panda-bear; FA) or the backward direction (e.g., ball-catch; BA). The results showed that priming for FA pairs completely evaporated under a high working memory load, but that it remained stable for BA and SYM pairs. This was taken to mean that prospective processes, which are assumed to cause FA priming, require cognitive resources, whereas retrospective processes, which lead to BA priming, are relatively effortless.
\end{abstract}

Keywords: working memory; automatic priming; strategic priming; asymmetric association 


\section{Introduction}

It is a well-known finding that the presentation of a related word (e.g., cat) enhances processing of a subsequently presented target (e.g., dog) compared to when the preceding word is unrelated (e.g., car). This phenomenon, called semantic priming, has been studied extensively because it is thought to provide insight into the structure of people's mental lexicon. Part of the research has been devoted to examining how semantic priming relates to individual characteristics such as age (Balota \& Duchek, 1988; Hutchison, Balota, Cortese, \& Watson, 2008), mental health (Pomarol-Clotet, Oh, Laws, \& McKenna, 2008), perceptual ability (Plaut \& Booth, 2000), or vocabulary knowledge (Yap, Tse, \& Balota, 2009). In the present paper, however, we focus on the relation between working memory capacity and semantic priming. Before reviewing the extant literature about this topic, we first describe the different sources of priming effects that have been put forth.

The term priming effect has been used in different contexts, but here it refers to the observation that the response to a target $(\log )$ is facilitated when it is preceded by a semantically related prime (cat) compared to when the prime is unrelated (car). For instance, when participants have to read aloud words (i.e., a pronunciation task) or judge whether a letter string forms an existing word (i.e., a lexical decision task), response times are faster and accuracy is higher for related prime-target pairs. These priming effects have been argued to arise as a result of automatic pre-activation processes and/or the use of strategies such as expectancy generation and semantic matching (see Neely, 1991, for a review).

Automatic priming emerges when the presentation of a related prime (partially) activates the target's representation, thereby lowering its recognition threshold. Processes such as these are conceived as automatic because they can occur without conscious awareness, intention and without interference from other mental activities (Posner \& Snyder, 1975). Most importantly for the present paper, semantic activation is assumed to be capacity 
free, hence the resulting priming effect should not be affected by imposing a secondary task (Neely \& Kahan, 2001).

Controlled priming, in contrast, takes place when participants adopt certain strategies to successfully tackle the task at hand. One strategy is to generate a number of potential targets based on the prime (i.e., expectancy generation, henceforth EG; see Becker, 1980). Concretely, when the prime is, for instance, cat, one might produce semantically related candidate targets such as $d o g$, pet, etc... This, in turn, facilitates target recognition if the target is included among the set of candidates. A second strategy involves retrospectively checking whether the target is related to the previously displayed prime (i.e., retrospective semantic matching, henceforth RSM). The rationale is that in a lexical decision task, detecting a relation between prime and target predicts the correct target response. That is, if prime and target are related, the target is always a word, whereas if they are unrelated, the target is usually a non-word. These contingencies might speed up responses in the related condition relative to the unrelated condition (Neely \& Keefe, 1989) ${ }^{1}$. In contrast to automatic priming, strategic priming is thought to be task-dependent and unstable across participants. The aim of the present article is to examine how these different sources of semantic priming depend on working memory capacity.

In the literature, there are a few correlational studies linking priming effects to executive functioning. For instance, Kiefer, Ahlegian, and Spitzer (2005) found a negative relation between verbal working memory capacity and priming, which was taken to mean that they have a common neural correlate. One explanation that has been advanced is that prefrontal dopamine activity modulates both performance on working memory tasks and activation spreading in semantic networks. The latter claim is supported by the finding that

\footnotetext{
${ }^{1}$ Note that RSM might also occur in the pronunciation task (see Thomas, Neely, \& O'Connor, 2012).
} 
the ingestion of L-dopa, a dopamine precursor, reduces indirect priming (Kischka et al., 1996). However, the negative correlation between priming and verbal working memory capacity found by Kiefer et al. was at a stimulus onset asynchrony (i.e., the time between prime onset and target onset, henceforth SOA) of $700 \mathrm{~ms}$. However, at an SOA of $200 \mathrm{~ms}$, extreme group analysis showed a larger priming effect for people with higher working memory capacity. If one also factors in that "pure" automatic priming has been argued to arise at short SOA's (Neely, 1991), it is unclear whether spreading activation is indeed related to working memory capacity.

In a recent study, Hutchison, Heap, Neely, and Thomas (2014) examined how EG and RSM are related to working memory capacity. To this end, they correlated priming effects for forward associates (e.g., panda-bear, henceforth FA), backward associates (e.g., ball-catch, henceforth BA) and symmetric associates (e.g., answer-question, henceforth SYM) with an attentional control component extracted from a battery consisting of working memory capacity (Operation Span) and attention (Stroop, Antisaccade) tests. This attentional control latent variable is argued to be the key component linking working memory capacity to performance across a wide range of aptitude tests and fluid intelligence measures (Conway, Kane, \& Engle, 2003). The rationale behind using asymmetric associations is that FA priming cannot be attributed to RSM because there is no backward target-prime association. Conversely, BA priming cannot be caused by EG because the absence of a forward primetarget relation means that the target will not be in the candidate set. This enables one to disentangle how these two strategic priming effects relate to attentional control. The results indicated that forward priming was greater for people having higher attentional control, which was taken to mean that EG requires cognitive resources (see also Hutchison, 2007, for corroborating evidence). Backward priming, on the other hand, was not positively related to 
attentional control. If anything the relation went in the opposite direction, suggesting that RSM is relatively effortless ${ }^{2}$.

The evidence reviewed thus far is all correlational in nature. To our knowledge, only a few studies manipulated working memory load while participants were concurringly performing a task designed to measure priming effects (Fuentes, Carmona, Agis, \& Catena, 1994; Posner, Sandson, Dhawan, \& Shulman, 1989; Sabb, Bilder, Chou, \& Bookheimer, 2007). Taken together, the evidence as to whether load influences semantic priming is mixed even within studies. That is, asking participants to do a verbal secondary task either reduced semantic priming (Posner et al., 1989, Experiment 1 and 3; Sabb et al., 2007; for foveal primes in Fuentes et al., 1994) or did not impact priming (Posner et al., 1989, Experiment 4 and 5; for parafoveal primes in Fuentes et al., 1994). When there is a decrease in the magnitude of the priming effect, it is mostly attributed to strategic processes being ineffectual under high load. But even if a load manipulation indeed impedes strategic priming, it remains unclear whether it disrupts EG, RSM or both ${ }^{3}$.

In summary, several studies about working memory and semantic priming use a correlational approach, which could be subject to alternative interpretations. As noted by Hutchison and colleagues (2014), other variables such as vocabulary knowledge or perceptual ability, which have been shown to correlate with semantic priming, could (partially) explain the pattern of results. The studies that manipulated working memory capacity are inconclusive as to whether a secondary task influences the magnitude of the priming effect and, if so,

\footnotetext{
${ }^{2}$ Our re-analyses of Hutchison et al.'s data (2014) demonstrates that the Attentional Control $x$ Type of Association x Priming interaction is still significant $(p=.04)$ if only the working memory capacity measure (OSPAN) is used, rather than the entire attentional control battery. ${ }^{3}$ Note that Neely, O'Connor, and Calabrese (2010) also manipulated cognitive load by varying the interval in-between the prime-target pairs. A shorter interval (i.e., $400 \mathrm{~ms}$ ) was argued to deplete attentional resources more than a longer interval (i.e., $2500 \mathrm{~ms}$ ). However, this is not a direct manipulation of working memory load and varying the pre-prime interval can affect the temporal grouping of the target with the current prime, relative to previous items, which has been shown to affect priming (e.g., Neill, Valdes, Terry, \& Gorfein, 1992).
} 
which priming mechanism(s) suffer from imposing a load. The present study addressed this issue using a traditional lexical decision task combined with a non-verbal working memory manipulation. We opted for a non-verbal secondary task instead of a verbal load manipulation to avoid having participants internally rehearse verbal content during the lexical decision task (Baddeley \& Hitch, 1974). In addition to constraining cognitive resources, a verbal working memory load would create a situation similar to a long-term priming design in which the prime and target are separated by unrelated filler words. This could in turn interfere with RSM, as it becomes harder to integrate prime and target when unrelated stimuli intervene, and spreading activation, as unrelated concepts may become activated as well. Therefore, in the present experiment, participants had to remember an easy or complex dot pattern while performing a lexical decision task. Furthermore, we used FA, BA and SYM pairs to disentangle effects of EG and RSM and SOA's of $200 \mathrm{~ms}$ and $1200 \mathrm{~ms}$ to tease apart automatic and strategic priming. Based on the findings discussed above, we expected that forward priming would be reduced under a high working memory load, whereas backward priming would remain stable or even increase.

\section{Method}

\section{Participants}

Participants were 80 first-year psychology students of the University of Leuven (11 men, 69 women, mean age 19 years), who participated in return for course credit. All participants were native Dutch speakers.

\section{Materials}

A total of 120 critical prime-target pairs were constructed (see Appendix A for all pairs and Table 1 for a summary of the stimulus characteristics). They consisted of 40 FA pairs, 40 BA pairs and 40 SYM pairs. Pairs were matched on associative strength based on the 
Dutch Word Association Database using only first associations (De Deyne, Navarro, \& Storms, 2013). Furthermore, targets were matched on length, contextual diversity (i.e., the number of contexts in which a word occurs, Keuleers, Brysbaert, \& New, 2010), word frequency and baseline response time and accuracy, both obtained from the Dutch Lexicon Project (Keuleers, Diependaele, \& Brysbaert, 2010). The 40 critical pairs per association type were randomly divided into eight lists, which were cycled through the load (high versus low load), SOA (200 ms versus $1200 \mathrm{~ms}$ ) and relatedness (related versus unrelated prime-target pairs) conditions. Unrelated pairs were formed by randomly recombining primes and targets within each list.

In addition to the 120 critical pairs, 80 filler SYM pairs and 120 word-nonword pairs were included, thereby conceptually replicating the design of Hutchison et al. (2014). The 120 word-nonword pairs were created in a similar fashion as in Thomas et al. (2012). Starting from symmetrically related pairs, nonwords were generated using the 120 targets as input for Wuggy, a Dutch pseudoword generator that obeys phonotactic constraints (Keuleers \& Brysbaert, 2010). Then, the thus-formed nonwords were re-paired at random with different, unrelated primes. This yielded a relatedness proportion of .60 (i.e., the proportion of word targets preceded by a semantically related prime) and also a nonword ratio of .60 (i.e., the proportion of unrelated pairs that comprise a nonword target).

The stimuli for the working memory load manipulation consisted of 4 x 4 matrices with 4 dots presented within 16 possible locations (see Figure 1). In the low load condition, the dots formed a straight line whereas the dots were semi-randomly scattered in the high load condition. The algorithm to create the latter patterns ensured that dots had no adjacent neighbors in either a horizontal or vertical direction and that there were maximally two dots on the main diagonals. In total, 151 different high load patterns were used in the experiment as a result of this procedure. 


\section{Procedure}

The procedure of the experiment is schematically depicted in Figure 2. First, participants were shown a fixation cross for $500 \mathrm{~ms}$, followed by a dot pattern that remained on the screen for $750 \mathrm{~ms}$. The participants' task was to remember the location of the dots. Next, the fixation cross reappeared for $500 \mathrm{~ms}$, followed by an uppercase prime (e.g., $B A L L$ ) for $150 \mathrm{~ms}$. A blank screen then appeared for 50 or $1050 \mathrm{~ms}$, thus yielding an SOA of respectively, 200 or $1200 \mathrm{~ms}$. Subsequently, a lowercase target stimulus (i.e., a word or a nonword; e.g., catch) appeared. Participants judged whether this letter string formed an existing Dutch word or not by pressing the arrow keys. The left arrow corresponded to word whereas the right arrow corresponded to nonword. A blank screen replaced the target as soon as participants responded or if $3000 \mathrm{~ms}$ elapsed without a response. In an attempt to keep working memory load constant over the two SOA conditions, the presentation duration of this blank screen depended on SOA. If SOA was $200 \mathrm{~ms}$, then the blank screen remained on the screen for $1800 \mathrm{~ms}$, whereas for an SOA of $1200 \mathrm{~ms}$ the blank screen was $800 \mathrm{~ms}$. The latter five events (i.e., fixation cross, prime, blank screen, target, blank screen) were repeated five times. Each sequence consisted of five different prime-target pairs, while SOA remained constant within the sequence. After the fifth repeat, an empty 4 x 4 matrix appeared and participants were asked to reproduce the initial dot pattern by clicking on the squares they thought contained a dot. There was no time limit on the pattern reproduction task. Once participants were satisfied with their response, they could click on a Done button that appeared below the matrix. This triggered a new cycle of events as shown in Figure 2. Finally, a blank screen was presented for $2000 \mathrm{~ms}$ between every cycle (i.e., the intercycle interval).

In total there were 64 cycles, which were split up in two blocks such that one block contained 32 long SOA cycles and the other block 32 short SOA cycles. A random half of 
those cycles featured a low load pattern whereas the other half featured a complex high load pattern. The order of the prime-target pairs within each condition was randomly determined and block order was counterbalanced over participants. Each block started with two practice cycles, one with a low load pattern and one with a high load pattern. Half of the practice targets were words, the other half nonwords and all pairs were unrelated. All stimuli were presented in the center of the screen against a grey background and participants never received feedback.

Before the start of the experiment, participants were told that they had to perform two tasks. One involved remembering a dot pattern, and in the other, they had to decide whether a lowercase target formed an existing word or not. They were also informed to silently read the briefly presented uppercase prime, which required no response ${ }^{4}$. The instructions for the lexical decision task stressed both speed and accuracy, whereas only accuracy was stressed for the dot memory task. Additionally, both tasks were said to be equally important. In between the two blocks, participants were given a break, but they could also briefly pause by refraining from clicking on the Done button after completing the dot pattern.

The experiment was programmed in Java and run on a Dell Pentium 4 with a 17.3inch CRT monitor. It was part of a series of unrelated experiments and took approximately 30 minutes.

\section{Results}

\section{Dot memory task}

As a manipulation check, we first compared performance on the low versus high load patterns. The mean number of correctly localized dots in the low load condition was

\footnotetext{
${ }^{4}$ The terms prime and target were not used in the actual instructions.
} 
significantly higher than in the high load condition $(M=3.8$ and 3.3 , respectively; $t(79)=$ $11.00, p<.001)$. High load patterns were indeed more difficult to remember, but not to the point that participants failed to comply (i.e., all participants performed significantly above chance, all $p$ 's $<.03)$.

\section{Lexical decision task}

Response times. Before analyzing the data, we removed error responses $(2.1 \%$ of the data) and outliers (another 2.5\%). Outlier removal occurred in two stages. First, only trials where a response was given before the $3000 \mathrm{~ms}$ deadline and of which the response time was above $250 \mathrm{~ms}$, were retained. Then, a cut-off value per participant was calculated (i.e., the mean plus three standard deviations). Response times exceeding this value were also removed.

By-subject and by-item ANOVA's were performed on the trimmed data with Relatedness (related or unrelated), Type of Association (BA, FA or SYM), Load (high or low) and SOA (long or short) as factors ${ }^{5}$. The analyses were run in $\mathrm{R}$ (version 3.0.1; R Core Team, 2013) using the aov.car and nice.anova functions from the afex package (Singmann, 2013). When appropriate, the Greenhouse-Geisser correction on the degrees of freedom was applied.

The results, summarized in Table 2 , revealed a significant main effect of Load $\left(F_{\mathrm{s}}(1\right.$, $79)=42.02, M S E=14,655, p<.001, \eta_{p}^{2}=.35 ; F_{\mathrm{i}}(1,117)=42.76, M S E=7,485, p<.001, \eta_{p}^{2}$ $=.27)$, a main effect of Relatedness $\left(F_{\mathrm{s}}(1,79)=65.41, M S E=13,160, p<.001, \eta_{p}{ }^{2}=.45\right.$; $\left.F_{\mathrm{i}}(1,117)=51.33, M S E=9,344, p<.001, \eta_{p}{ }^{2}=.30\right)$, a main effect of Type of Association $\left(F_{\mathrm{s}}(1.98,156.14)=12.34, M S E=11,847, p<.001, \eta_{p}^{2}=.14 ; F_{\mathrm{i}}(2,117)=7.46, M S E=\right.$

\footnotetext{
${ }^{5}$ The same analyses were run for log-transformed and z-transformed response times, which yielded the same conclusions. Furthermore, multilevel analyses were performed with random participant and item intercepts and random slopes where appropriate. These analyses replicated the findings reported in the main text, but sometimes failed to reach convergence.
} 
$\left.10,649, p<.001, \eta_{p}^{2}=.11\right)$ and a main effect of $\operatorname{SOA}\left(F_{\mathrm{s}}(1,79)=4.20, M S E=54,302, p=\right.$ $\left..04, \eta_{p}{ }^{2}=.05 ; F_{\mathrm{i}}(1,117)=23.23, M S E=5,089, p<.001, \eta_{p}{ }^{2}=.17\right)$. Besides the four main effects, only the Load x Type of Association x Relatedness interaction proved significant in both subject and item analyses $\left(F_{\mathrm{s}}(1.94,153.13)=4.48, M S E=8,798, p=.01, \eta_{p}{ }^{2}=.05 ; F_{\mathrm{i}}(2\right.$, $\left.117)=3.84, M S E=6,242, p=.02, \eta_{p}{ }^{2}=.06\right)$. The main effects of Load and Relatedness are quite straightforward: response times are lower when participants have to remember an easy pattern and when a related prime precedes the target. The effect of Type of Association is somewhat unexpected, given that BA, FA and SYM pairs were matched on response times obtained from Keuleers et al. (2010). SOA also appears to influence response times, such that a long SOA results in faster response times to the targets. Follow-up analyses revealed that this effect is limited to the first prime-target pair of a cycle. ANOVA's on the response times of the last four pairs per cycle with only SOA as a factor showed no significant effect $\left(F_{\mathrm{s}}(1\right.$, $79)=0.10, M S E=4,846, p=.75, \eta_{p}^{2}=.00 ; F_{\mathrm{i}}(1,119)=1.06, M S E=1,717, p=.31, \eta_{p}^{2}=$ $.01)$, whereas for the first pairs there was a strong $\operatorname{SOA}$ effect $\left(F_{\mathrm{s}}(1,79)=30.71, M S E=\right.$ $\left.10,676, p<.001, \eta_{p}{ }^{2}=.28 ; F_{\mathrm{i}}(1,119)=17.79, M S E=17,576, p<.001, \eta_{p}{ }^{2}=.13\right)$. It is conceivable that participants were more actively processing the dot pattern during the interval between the first prime and target of a cycle. This probably delays responses in the lexical decision task, especially when SOA is short.

Examining the Load x Type of Association x Relatedness interaction, thereby collapsing over SOA as it did not interact with any of the other factors, we see that the interaction is driven by the FA pairs in the high load condition as they showed no priming effect. In contrast, all other conditions resulting from combining Type of Association with Load yielded a significant priming effect of around $50 \mathrm{~ms}$. Note though that this pattern of results cannot be explained by the (unanticipated) faster baseline response times of the FA pairs, as a strong priming effect did emerge for these pairs in the low load condition. 
Nevertheless, an additional non-planned analysis was conducted to address this issue. That is, an ANCOVA was performed on the item level priming effect averaged over participants with Load and Type as factors and Baseline RT (i.e., the z-transformed response time per item obtained by averaging across participants and conditions) as a covariate. In line with the previous analyses, the results revealed a significant Load x Type interaction $(F(2,116)=3.28$, $\left.M S E=6,292, p=.04, \eta_{p}{ }^{2}=.05\right)$. None of the other effects reached significance.

In addition, the items from the three association types were not a priori matched in terms of prime characteristics. However, as demonstrated by Hutchison et al. (2008), such variables may influence the magnitude of the priming effect as well. Specifically, Hutchison and colleagues found a positive correlation between the priming effect in a lexical decision task and the baseline response time to the unrelated prime. Although the influence of the latter variable on the magnitude of the priming effect was smaller than baseline response time to the target, an additional ANCOVA was conducted with Load and Type as factors and Baseline Unrelated Prime RT (i.e., the z-transformed response time per unrelated prime obtained from the Dutch Lexicon Project) as a covariate. The results again showed only a significant Load $\mathrm{x}$ Type interaction $\left(F(2,92)=4.96, M S E=5,925, p<.01, \eta_{p}{ }^{2}=.10\right)^{6}$.

Looking at the priming effects per participant, one can also discern a significant pattern of underadditivity in the low load condition, in that SYM priming is smaller than the sum of BA and FA priming $(t(79)=2.92, p<.01)$. This result mimics the underadditivity found by Hutchison et al. (2014), but contrasts with the additive pattern reported in Thomas et al. (2012). In the high load condition, on the other hand, the sum of BA and FA priming is not significantly different from SYM priming, indicating additivity of priming $(t(79)=0.00, p=$

\footnotetext{
${ }^{6}$ The degrees of freedom in the denominator are smaller in this analysis because baseline response times were not available for all primes. An ANCOVA that simultaneously included Baseline Unrelated Prime RT and Baseline RT revealed a Load x Type interaction $(F(2,91)=$ $\left.4.41, M S E=5,947, p=.01, \eta_{p}{ }^{2}=.09\right)$ and a main effect of Baseline RT $(F(1,91)=4.57, M S E$ $=9,107, p=.04, \eta_{p}{ }^{2}=.05$ ).
} 
.997). However, this is due to the fact that FA priming is absent and BA priming is statistically indistinguishable from SYM priming $(t(79)=0.09, p=.93)$.

Error Responses. Overall, the number of error responses was quite low: only $2.1 \%$ of the items were erroneously classified as a nonword. This low number of errors is especially remarkable if one factors in the dual task procedure. A consequence is that priming may go undetected due to floor effects. Nevertheless, multilevel logistic regression analyses were performed on the responses to ensure that the observed pattern in Table 2 cannot be attributed to a speed-accuracy trade-off. The analyses were conducted for BA, FA and SYM pairs separately with Load, SOA and Relatedness as factors (see Table 3). The results revealed only a significant priming effect for BA pairs $(Z=2.57, p=.01)$, but not for FA pairs $(Z=0.02, p$ $=.98)$ and SYM pairs $(Z=1.64, p=.10)$. None of the interactions reached significance in any of the analyses (all $p$ 's $>.38$ ). One can thus safely interpret the response time effects, as they are not driven by a speed-accuracy trade-off.

\section{Discussion}

The present study sought to examine whether automatic and strategic priming require working memory capacity. To this end, a double task procedure was employed to manipulate the cognitive resources available to participants. Furthermore, to separate prospective and retrospective processes, we compared FA pairs with BA pairs and SYM pairs. Priming for FA pairs is thought to arise solely due to prospective processes, because there is no backward relation going from the target to the prime. Conversely, priming for BA pairs is attributed to retrospective processes, as there is no forward relation between prime and target. The results of the present study indicate that imposing a working memory load interferes with prospective priming, but not with retrospective priming. That is, priming for FA pairs decreased in the high load condition compared to the low load condition, whereas it remained constant for BA 
pairs. Not only did the priming effect for FA pairs decrease, it completely disappeared under a high working memory load. Taken together, these findings are in line with those from Hutchison et al. (2014) and indicate that EG, a prospective process, depends on working memory capacity (as suggested by Neely, 1977), whereas RSM, a retrospective process, is relatively effortless. Moreover, the pattern of underadditivity in the low load condition (i.e., BA + FA priming $>$ SYM priming), where FA pairs do show a priming effect, might indicate that EG and RSM are not independent processes. The lack of a load effect on priming for SYM pairs also suggests that EG and RSM are interdependent. Both EG and RSM presumably contribute to the priming effect for SYM pairs in the low load condition, whereas EG does not play a role in the high load condition as evidenced by the null priming effect for FA pairs in the high load condition. This would entail that in absence of EG, RSM can compensate to produce equal-sized priming effects if a backward association exists.

The fact that FA pairs yield no priming effect under a high load has also implications for automatic accounts of priming. These assume that the presentation of a related prime automatically activates the target's representation. However, our findings suggest that if cognitive resources are depleted, prospective priming might be disrupted. Hence, one might question whether target activation is capacity free and thus actually automatic. This resonates with the proposition that semantic priming requires attention (Stolz \& Besner, 1999). Furthermore, it is in line with Experiment 1 of Martens and Kiefer (2009). In this study, participants performed an easy or difficult task prior to each masked priming trial. The results showed no priming effect when the primary task was difficult unless there was enough time between the primary and the secondary task (i.e., the masked priming task). This was taken to mean that unconscious automatic processes require top-down attentional control. These results combined with the present findings might put the traditionally used distinction between automatic and strategic priming in perspective. The latter is thought to arise as a 
result of volatile processes such as EG and RSM, which require cognitive resources and are under the (conscious) control of participants. However, this study suggests that RSM does not meet these criteria (see also Hutchison et al., 2014). In addition, prospective target activation seems to require some attentional control. Hence, its status as being purely automatic in terms of Posner and Snyder's criteria (1975) appears questionable.

Thus far the term "target activation" has been used to refer to the entire process of prime activation that spreads to related concepts, ultimately leading to (pre-) activation of the target. However, the load manipulation could in principle have had an effect on three different processes: semantic activation of the prime, spreading activation from the prime to the target, or activation of the target itself. An explanation in terms of a secondary task interfering with semantic activation of a prime would go against the capacity free assumption of semantic activation (Neely \& Kahan, 2001), but would be in line with the claim from Stolz and Besner (1999) that semantic processing depends on attentional control. It should be noted though that the priming effects for BA and SYM pairs under high load suggest that the prime is encoded and processed up to a certain level. Alternatively, it is possible that a high working memory load disrupts activation spreading. Such an account would be in line with recent findings that semantic activation is automatic (and thus capacity free), but that it does not necessarily produce behavioral semantic priming effects (Heil, Rolke, \& Pecchinenda, 2004; Hutchison \& Bosco, 2007). However, the present study is relatively agnostic as to whether load interferes with prime activation, spreading activation and/or target activation itself. It does suggest that the process as a whole is not capacity free.

In sum, the present research provides insight into the different processes involved in semantic priming. It demonstrates that prospective processes, such as feed-forward target activation and expectancy generation require cognitive resources, whereas retrospective semantic matching is largely impervious to working memory capacity constraints. 


\section{Acknowledgments}

Tom Heyman is a research assistant of the Research Foundation-Flanders (FWO-

Vlaanderen). Correspondence should be addressed to Tom Heyman, Department of

Experimental Psychology, University of Leuven, Tiensestraat 102, 3000 Leuven, Belgium. Email: tom.heyman@ppw.kuleuven.be 


\section{References}

Baddeley, A. D., \& Hitch, G. (1974). Working memory. In G. H. Bower (Ed.), The psychology of learning and motivation (Vol. 8, pp. 47-89). New York: Academic Press.

Balota, D. A., \& Duchek, J. M. (1988). Age-related differences in lexical access, spreading activation, and simple pronunciation. Psychology and Aging, 3(1), 84-93. doi:10.1037/0882-7974.3.1.84

Becker, C. A. (1980). Semantic context effects in visual word recognition: An analysis of semantic strategies. Memory \& Cognition, 8(6), 493-512. doi:10.3758/BF03213769

Conway, A. R. A., Kane, M. J., \& Engle, R. W. (2003). Working memory capacity and its relation to general intelligence. Trends in Cognitive Sciences, 7(12), 547-552. doi:10.1016/j.tics.2003.10.005

De Deyne, S., Navarro, D. J., \& Storms, G. (2013). Better explanations of lexical and semantic cognition using networks derived from continued rather than single-word associations. Behavior Research Methods, 45(2), 480-498. doi:10.3758/s13428-0120260-7

Fuentes, L. J., Carmona, E., Agis, I. F., \& Catena, A. (1994). The role of the anterior attention system in semantic processing of both foveal and parafoveal words. Journal of Cognitive Neuroscience, 6(1), 17-25. doi: 10.1162/jocn.1994.6.1.17

Heil, M., Rolke, B., \& Pecchinenda, A. (2004). Automatic semantic activation is no myth: Semantic context effects on the N400 in the letter-search task in the absence of response time effects. Psychological Science, 15(12), 852-857. doi:10.1111/j.09567976.2004.00766.x 
Hutchison, K. A. (2007). Attentional control and the relatedness proportion effect in semantic priming. Journal of Experimental Psychology: Learning, Memory, and Cognition, 33(4), 645-662. doi:10.1037/0278-7393.33.4.645

Hutchison, K. A., Balota, D. A., Cortese, M. J., \& Watson, J. M. (2008). Predicting semantic priming at the item level. The Quarterly Journal of Experimental Psychology, 61(7), 1036-1066. doi:10.1080/17470210701438111

Hutchison, K. A., \& Bosco, F. A. (2007). Congruency effects in the letter search task: Semantic activation in the absence of priming. Memory \& Cognition, 35(3), 514-525. doi:10.3758/BF03193291

Hutchison, K. A., Heap, S. J., Neely, J. H., \& Thomas, M. A. (2014, February 17). Attentional control and asymmetric associative priming. Journal of Experimental Psychology: Learning, Memory, and Cognition. Advance online publication. doi:10.1037/a0035781

Keuleers, E., \& Brysbaert, M. (2010). Wuggy: A multilingual pseudoword generator. Behavior Research Methods, 42(3), 627-633. doi:10.3758/BRM.42.3.627

Keuleers, E., Brysbaert, M., \& New, B. (2010). SUBTLEX-NL: A new frequency measure for Dutch words based on film subtitles. Behavior Research Methods, 42(3), 643-650. 10.3758/BRM.42.3.643

Keuleers, E., Diependaele, K., \& Brysbaert, M. (2010). Practice effects in large-scale visual word recognition studies: A lexical decision study on 14,000 Dutch mono-and disyllabic words and nonwords. Frontiers in Psychology, 1. doi:10.3389/fpsyg.2010.00174

Kiefer, M., Ahlegian, M., \& Spitzer, M. (2005). Working memory capacity, indirect semantic priming, and stroop interference: Pattern of interindividual prefrontal performance 
differences in healthy volunteers. Neuropsychology, 19(3), 332-344. doi:10.1037/0894-4105.19.3.332

Kischka, U., Kammer, T., Maier, S., Weisbrod, M., Thimm, M., \& Spitzer, M. (1996). Dopaminergic modulation of semantic network activation. Neuropsychologia, 34(11), 1107-1113. doi:10.1016/0028-3932(96)00024-3

Martens, U., \& Kiefer, M. (2009). Specifying attentional top-down influences on subsequent unconscious semantic processing. Advances in Cognitive Psychology, 5, 56-68. doi:10.2478/v10053-008-0067-3

Neely, J. H. (1977). Semantic priming and retrieval from lexical memory: Roles of inhibitionless spreading activation and limited-capacity attention. Journal of Experimental Psychology: General, 106, 226-254. doi:10.1037/0096-3445.106.3.226

Neely, J. H. (1991). Semantic priming effects in visual word recognition: A selective review of current findings and theories. In D. Besner \& G. W. Humphreys (Eds.), Basic processes in reading: Visual word recognition (Vol. 11, pp. 264-336). Hillsdale, NJ: Erlbaum.

Neely, J. H., \& Kahan, T. A. (2001). Is semantic activation automatic? A critical reevaluation. In H. L. Roediger, J. S. Nairne, I. Neath, \& A. M. Suprenant (Eds.), The nature of remembering: Essays in honor of Robert G. Crowder (pp. 69-93).

Washington, DC: American Psychological Association. doi: 10.1037/10394-005

Neely, J. H., \& Keefe, D. E. (1989). Semantic context effects on visual word processing: A hybrid prospective/retrospective processing theory. In G. H. Bower (Ed.), The psychology of learning and motivation (Vol. 24, pp. 207-248). New York: Academic Press. 
Neely, J. H., O’Connor, P. A., \& Calabrese, G. (2010). Fast trial pacing in a lexical decision task reveals a decay of automatic semantic activation. Acta Psychologica, 133(2), 127-136. doi:10.1016/j.actpsy.2009.11.001

Neill, W. T., Valdes, L. A., Terry, K. M., \& Gorfein, D. S. (1992). Persistence of negative priming: II. Evidence for episodic trace retrieval. Journal of Experimental Psychology: Learning, Memory, and Cognition, 18(5), 993-1000. doi:10.1037/02787393.18.5.993

Plaut, D. C., \& Booth, J. R. (2000). Individual and developmental differences in semantic priming: Empirical and computational support for a single-mechanism account of lexical processing. Psychological Review, 107(4), 786-823. doi:10.1037/0033295X.107.4.786

Pomarol-Clotet, E., Oh, T. M. S. S., Laws, K. R., \& McKenna, P. J. (2008). Semantic priming in schizophrenia: Systematic review and meta-analysis. The British Journal of Psychiatry, 192(2), 92-97. doi:10.1192/bjp.bp.106.032102

Posner, M. I., Sandson, J., Dhawan, M., \& Shulman, G. L. (1989). Is word recognition automatic? A cognitive-anatomical approach. Journal of Cognitive Neuroscience, l(1), 50-60. doi: 10.1162/jocn.1989.1.1.50

Posner, M. I., \& Snyder, C. R. R. (1975). Attention and cognitive control. In R. L. Solso (Ed.), Information processing and cognition: The Loyola symposium (pp. 55-86). Hillsdale, NJ: Erlbaum.

R Core Team (2013). R: A language and environment for statistical computing. R Foundation for Statistical Computing, Vienna, Austria, http://www.R-project.org/.

Sabb, F. W., Bilder, R. M., Chou, M., \& Bookheimer, S. Y. (2007). Working memory effects on semantic processing: Priming differences in pars orbitalis. Neuroimage, 37(1), 311-322. doi:10.1016/j.neuroimage.2007.04.050 
Singmann, H. (2013). afex: Analysis of Factorial Experiments. R package version 0.6-82, http://CRAN.R-project.org/package=afex

Stolz, J. A., \& Besner, D. (1999). On the myth of automatic semantic activation in reading. Current Directions in Psychological Science, 8(2), 61-65. doi:10.1111/14678721.00015

Thomas, M. A., Neely, J. H., \& O’Connor, P. (2012). When word identification gets tough, retrospective semantic processing comes to the rescue. Journal of Memory and Language, 66(4), 623-643. doi:10.1016/j.jml.2012.02.002

Yap, M. J., Tse, C.-S., \& Balota, D. A. (2009). Individual differences in the joint effects of semantic priming and word frequency revealed by RT distributional analyses: The role of lexical integrity. Journal of Memory and Language, 61(3), 303-325. doi:10.1016/j.jml.2009.07.001 
Table 1

Mean values of Target attributes and of Prime-Target Association Strengths for the Different Association Types.

\begin{tabular}{lllll}
\hline Factor & BA pairs & FA pairs & SYM pairs & $F$ or $t$ \\
\hline Forward association strength & .00 & .51 & .51 & 0.03 \\
Backward association strength & .50 & .00 & .51 & 0.21 \\
Contextual diversity & 2.90 & 2.90 & 2.95 & 0.11 \\
Word frequency & 3.11 & 3.11 & 3.22 & 0.36 \\
Length & 5.23 & 5.25 & 5.33 & 0.06 \\
Baseline response time & 566 & 565 & 566 & 0.04 \\
Baseline accuracy & .98 & .99 & .98 & 0.74
\end{tabular}

Note: Contextual diversity is the log-transformed number of contexts in which a certain word occurs (Keuleers et al., 2010). Word frequency is the log-transformed total number of occurrences. Forward and backward association strength were derived from the Dutch Word Association Database (De Deyne, Navarro, \& Storms, 2013). Baseline response time and accuracy were obtained from Keuleers, Diependaele, and Brysbaert (2010). The last column gives the $F$ or $t$ values obtained from a statistical comparison of the association types on the different characteristics. None of the statistical tests came close to reaching significance (all $p ’ s>.48)$. 
Table 2

Mean Response Times to the Critical Targets as a Function of Load, Type of Association, Relatedness and SOA.

\begin{tabular}{|c|c|c|c|c|}
\hline & \multicolumn{2}{|c|}{ SOA 200} & \multicolumn{2}{|c|}{ SOA 1200} \\
\hline & HIGH LOAD & LOW LOAD & HIGH LOAD & LOW LOAD \\
\hline \multicolumn{5}{|l|}{ FA pairs } \\
\hline Unrelated & 837 & 810 & 801 & 778 \\
\hline Related & 835 & 755 & 799 & 733 \\
\hline Priming & $2[-41,45]$ & $55[24,85]$ & $2[-33,38]$ & $44[15,74]$ \\
\hline \multicolumn{5}{|l|}{ BA pairs } \\
\hline Unrelated & 869 & 842 & 857 & 822 \\
\hline Related & 814 & 792 & 808 & 779 \\
\hline Priming & $55[17,93]$ & $50[17,83]$ & $49[21,78]$ & $43[15,71]$ \\
\hline \multicolumn{5}{|l|}{ SYM pairs } \\
\hline Unrelated & 851 & 811 & 837 & 810 \\
\hline Related & 817 & 769 & 761 & 755 \\
\hline Priming & $34[-3,71]$ & $43[10,75]$ & $76[44,108]$ & $55[26,83]$ \\
\hline
\end{tabular}

Note: The by-subject priming effects per condition are printed in bold with the $95 \%$ confidence intervals in brackets. 
Table 3

Proportion of Error Responses to the Critical Targets as a Function of Load, Type of Association, Relatedness and SOA.

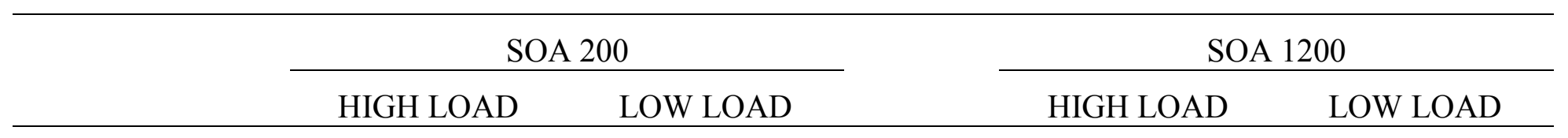

FA pairs

$\begin{array}{lllll}\text { Unrelated } & .02 & .02 & .01 & .01 \\ \text { Related } & .01 & .02 & .01 & .01\end{array}$

BA pairs

$\begin{array}{lllll}\text { Unrelated } & .03 & .05 & .05 & .04 \\ \text { Related } & .01 & .02 & .01 & .02\end{array}$

SYM pairs

Unrelated

.02

.01

.03

.03

Related

.02

.01

.01

.01 

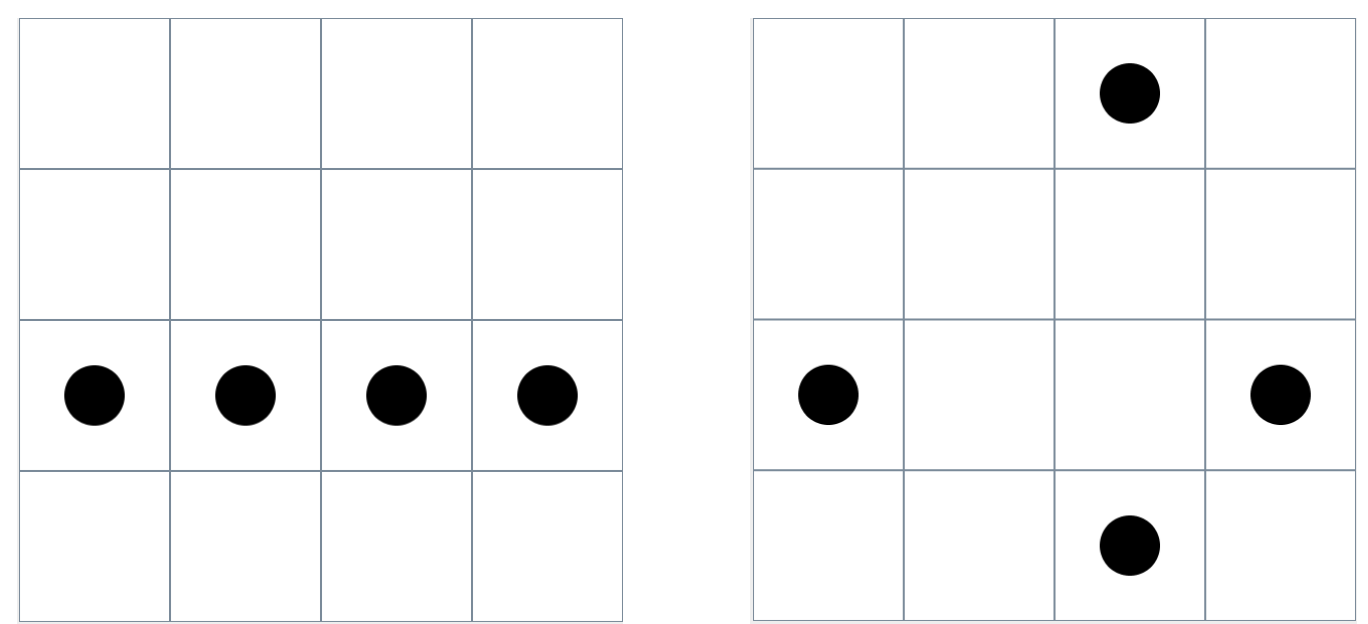

Figure 1. Example of a low load dot memory pattern (left panel) and a high load pattern (right panel). 


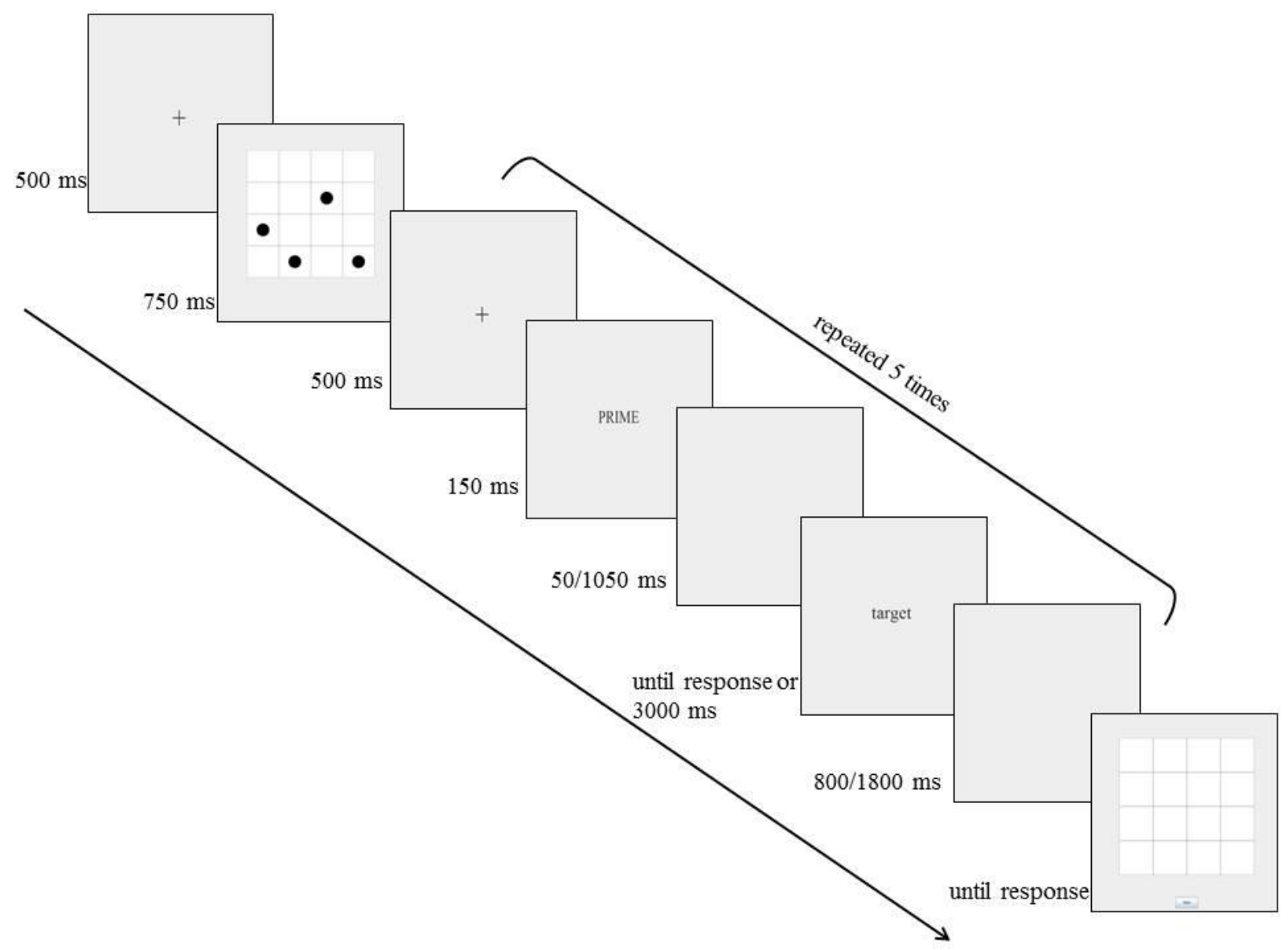

Figure 2. Flow of the experiment. The duration of the blank screen after the prime and the target depends on the SOA condition (see main text). 


\section{Appendix A}

The critical prime-target pairs used in the experiment. The first two columns contain the English translations, with the original Dutch words in parentheses. The third column specifies the type of association.

\begin{tabular}{|c|c|c|}
\hline Primes & Targets & Type of Association \\
\hline $\operatorname{man}(\operatorname{man})$ & guy (vent) & $\mathrm{BA}$ \\
\hline boat (boot) & deck (dek) & BA \\
\hline king (koning) & palace (paleis) & BA \\
\hline wet (nat) & moisture (vocht) & BA \\
\hline together (samen) & each other (elkaar) & BA \\
\hline beer (bier) & bar (café) & BA \\
\hline everyone (iedereen) & all (alle) & BA \\
\hline fear (angst) & to fear (vrezen) & BA \\
\hline holiday (vakantie) & hotel (hotel) & BA \\
\hline figure (getal) & six (zes) & BA \\
\hline cold (koud) & wintry (winters) & BA \\
\hline dangerous (gevaarlijk) & risky (riskant) & BA \\
\hline plane (vliegtuig) & pilot (piloot) & BA \\
\hline shop (winkel) & costumer (klant) & BA \\
\hline good (goed) & best (best) & BA \\
\hline sea (zee) & coast (kust) & BA \\
\hline I (ik) & oneself (zichzelf) & BA \\
\hline word (woord) & term (term) & BA \\
\hline gossip (roddel) & rumour (gerucht) & BA \\
\hline ball (bal) & to catch (vangen) & BA \\
\hline sun (zon) & to ray (stralen) & BA \\
\hline big (groot) & spacious (ruim) & BA \\
\hline warm (warm) & coat (jas) & BA \\
\hline woman (vrouw) & she (zij) & BA \\
\hline a lot (veel) & thousand (duizend) & BA \\
\hline girl (meisje) & chick (griet) & BA \\
\hline tasty (lekker) & cookies (koekjes) & BA \\
\hline
\end{tabular}




\begin{tabular}{|c|c|}
\hline chess (schaken) & move (zet) \\
\hline war (oorlog) & battlefield (slagveld) \\
\hline quick (snel) & soon (gauw) \\
\hline house (huis) & to build (bouwen) \\
\hline money (geld) & fortune (fortuin) \\
\hline photo (foto) & portrait (portret) \\
\hline whole (heel) & intact (intact) \\
\hline foot (voet) & step (stap) \\
\hline baby (baby) & cradle (wieg) \\
\hline pain (pijn) & to hurt (kwetsen) \\
\hline car (auto) & brake (rem) \\
\hline end (einde) & ending (afloop) \\
\hline to eat (eten) & menu (menu) \\
\hline pricey (prijzig) & expensive (duur) \\
\hline panda (panda) & bear (beer) \\
\hline concert (concert) & music (muziek) \\
\hline pitch (pek) & black (zwart) \\
\hline chorus (refrein) & song (lied) \\
\hline selection (selectie) & choice (keuze) \\
\hline lasso (lasso) & cowboy (cowboy) \\
\hline liqueur (likeur) & beverage (drank) \\
\hline pedicure (pedicure) & feet (voeten) \\
\hline rattle (ratel) & snake (slang) \\
\hline flake (vlok) & snow (sneeuw) \\
\hline plague (pest) & disease (ziekte) \\
\hline outlook (uitkijk) & tower (toren) \\
\hline proper (keurig) & neat (netjes) \\
\hline to launch (lanceren) & rocket (raket) \\
\hline din (rumoer) & noise (lawaai) \\
\hline debut (debuut) & beginning (begin) \\
\hline comedy (komedie) & to laugh (lachen) \\
\hline crumb (kruimel) & bread (brood) \\
\hline mouth (monding) & river (rivier) \\
\hline
\end{tabular}




\begin{tabular}{|c|c|c|}
\hline vocal (vocaal) & voice (stem) & FA \\
\hline to wake (wekken) & to get up (opstaan) & FA \\
\hline filter (filter) & coffee (koffie) & FA \\
\hline sweeper (veger) & brush (borstel) & FA \\
\hline squint (scheel) & eyes (ogen) & FA \\
\hline salami (salami) & sausage (worst) & FA \\
\hline dock (dok) & port (haven) & FA \\
\hline lump (klont) & sugar (suiker) & FA \\
\hline yawn (geeuw) & tired (moe) & FA \\
\hline October (oktober) & fall (herfst) & FA \\
\hline blank (blanco) & white (wit) & FA \\
\hline somersault (koprol) & gymnastics (turnen) & FA \\
\hline clod (kluit) & earth (aarde) & FA \\
\hline stale (goor) & dirty (vies) & FA \\
\hline tow (takel) & truck (wagen) & FA \\
\hline cobble (kassei) & stone (steen) & FA \\
\hline splinter (splinter) & wood (hout) & FA \\
\hline toxic (toxisch) & poisonous (giftig) & FA \\
\hline drought (droogte) & desert (woestijn) & FA \\
\hline tragedy (tragedie) & drama (drama) & FA \\
\hline water (water) & to drink (drinken) & SYM \\
\hline bow (boog) & arrow (pijl) & SYM \\
\hline thunder (donder) & lightning (bliksem) & SYM \\
\hline crazy (gek) & fool (zot) & SYM \\
\hline often (vaak) & frequently (dikwijls) & SYM \\
\hline pity (jammer) & regrettable (spijtig) & SYM \\
\hline to understand (begrijpen) & to understand (verstaan) & SYM \\
\hline broken (stuk) & damaged (kapot) & SYM \\
\hline proud (fier) & proud (trots) & SYM \\
\hline scissors (schaar) & to cut (knippen) & SYM \\
\hline nervous (zenuwachtig) & nervous (nerveus) & SYM \\
\hline calm (kalm) & quiet (rustig) & SYM \\
\hline anti (anti) & against (tegen) & SYM \\
\hline
\end{tabular}




\begin{tabular}{lll} 
unique (uniek) & single (enig) & SYM \\
yet (al) & already (reeds) & SYM \\
grief (verdriet) & to cry (wenen) & SYM \\
way (wijze) & manner (manier) & SYM \\
normal (normaal) & ordinary (gewoon) & SYM \\
every (ieder) & each (elk) & SYM \\
shut (toe) & closed (dicht) & SYM \\
swelling (gezwel) & tumor (tumor) & SYM \\
drunk (dronken) & intoxicated (zat) & SYM \\
mist (mist) & fog (nevel) & SYM \\
itch (jeuk) & to scratch (krabben) & SYM \\
serious (serieus) & grave (ernstig) & SYM \\
marriage (huwelijk) & wedding (trouw) & SYM \\
nun (non) & sister (zuster) & SYM \\
angry (kwaad) & mad (boos) & SYM \\
translator (vertaler) & interpreter (tolk) & SYM \\
to conjure (toveren) & magic (magie) & SYM \\
uncle (oom) & uncle (nonkel) & SYM \\
opinion (opinie) & opinion (mening) & SYM \\
answer (antwoord) & question (vraag) & SYM \\
to sleep (slapen) & bed (bed) & SYM \\
long (lang) & short (kort) & SYM \\
sheep (schaap) & wool (wol) & SYght (juist) \\
above (boven) & below (onder) & SYM \\
jungle (jungle) & jungle (oerwoud) & SYM \\
correct (correct) & book (boek) & \\
\hline
\end{tabular}

